
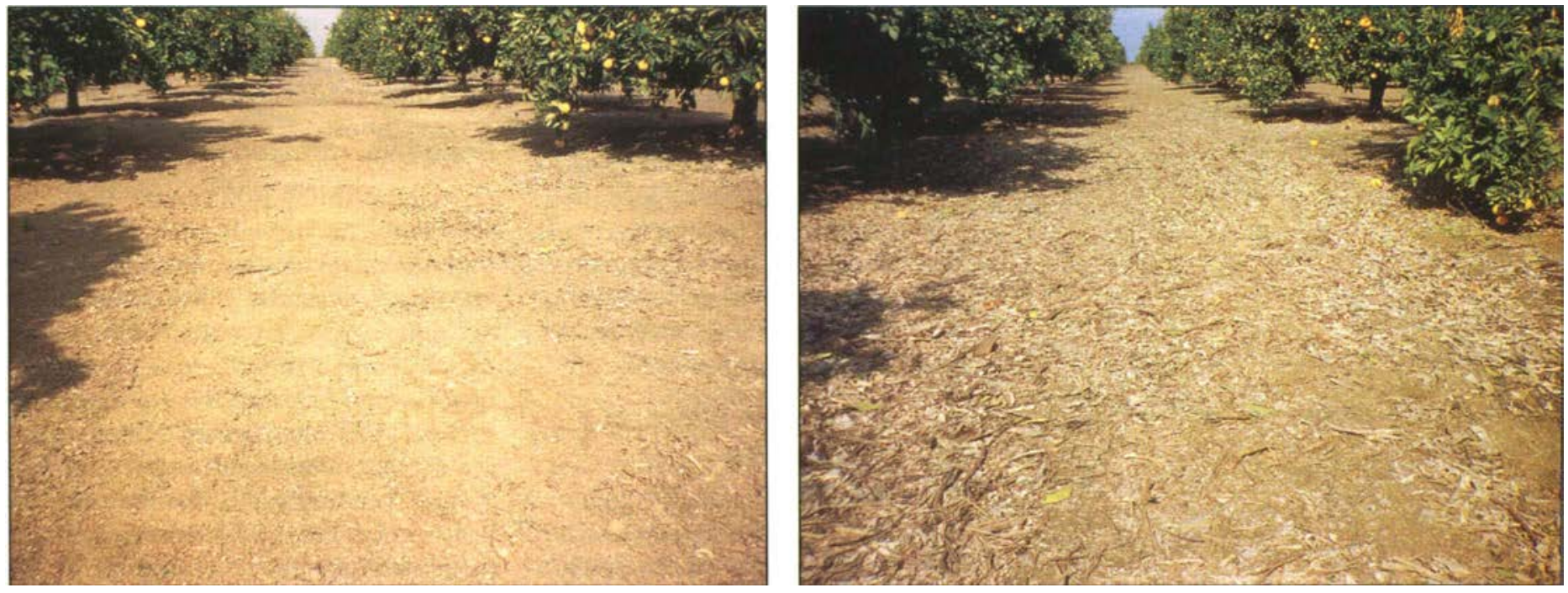

In the pruning experiment, the raked area, left, stored more heat in the soil and had a higher nighttime air temperature than the area covered with unraked shredded prunings, right.

\title{
Cover crops, mulch lower night temperatures in citrus
}

\author{
Neil V. O'Connell $\square$ Richard L. Snyder
}

\begin{abstract}
Winter often brings cold temperatures that can damage fruit or foliage in the San Joaquin Valley, posing an economic threat to citrus producers. Our experiments show that cover crops or mulch can lower minimum nighttime temperatures $0.9^{\circ} \mathrm{F}$ to $2.2^{\circ} \mathrm{F}$ in orchards, increasing the threat of freeze (frost) damage. Wind machines are typically used to protect commercial acreage from frost by mixing warmer air aloft with colder air near the surface, thus maintaining warmer minimum temperatures within the orchard. In locations where wind machines are not cost effective, management of the orchard floor is even more important. By using temperature forecast models that adjust for cover crops and mulches, growers can use wind machines more efficiently. Regardless, the decision to use cover crops must take into account all of their cultural benefits and drawbacks.
\end{abstract}

The potential for cover crops to lower nighttime temperatures has long been a concern among citrus producers. It is well known that bare soil has a greater capacity to absorb incoming radiation during daylight hours and transfer heat back to the surface at night (Gradwell 1963; Cochran et al. 1967; Fritton et al. 1976; Fritton and Martsolf 1981). Cover crops reflect more solar radiation, allowing less to reach the soil surface. They also evaporate more water from the surface soil layer, reducing its thermal conductivity and heat capacity. As a result, less energy is captured at the drier soil surface, and heat transfer and storage are impeded. Consequently, bare soil has better heat storage during the day and improved heat transfer during the day and night.

In addition, limited observations and trials suggest that citrus orchards with groundcover of sufficient height and density have lower air temperatures than orchards with bare ground (Pehrson 1989). Similar observations have been made for deciduous trees (Snyder and Connell 1993) and in grape vineyards (Donaldson et al. 1993).

The extent of freeze damage is related to how far the temperature drops below the damage threshold and the duration at the minimum temperature. Cover crops increase reflection of incoming radiation and shade the soil surface underneath. Groundcovers also remove water from upper layers of the soil and reduce thermal conductivity and heat capacity. Therefore, soil heat storage during daylight is reduced when a cover crop is present.

Similarly, USDA, UC and the University of Arizona have historically maintained that leaving shredded prunings on the orchard floor lowers the orchard temperature. Like cover crops, shredded material theoretically will reduce the amount of solar radiation reaching the soil surface. Therefore, the absence of cover crop and shredded material should enhance daytime heat storage. In light of these phenomena, citrus growers have been reluctant to allow vegetation on the orchard floor.

Recently, there is new interest in using cover crops in citrus orchards be- 
(over weeks and months) and the short term (on a daily basis), removing prunings improves freeze protection.

\section{Cover crop comparisons}

In the 1995 cover-crop experiment, the cover-crop treatment had lower nighttime temperatures and greater potential for freeze damage, as demonstrated by the treatment temperature traces from 9 A.M. on March 22 to 6 A.M. on March 25 (fig. 3). The effects of weather on temperature and treatment benefits are complicated. On March 22, weather conditions were sunny and windy during the day. Clouds formed in the evening and rain started at about 10 P.M. While it was raining, the temperature of the two treatments was nearly the same, and stayed about the same until about 1 P.M. on March 23. During March 23, the bare-ground treatment was warmed more by the sun and increased to a higher air temperature than the cover-crop plot. During the night of March 23, the treatment temperatures separated somewhat, but rainfall around midnight temporarily stopped the separation. The next day, the bare-ground temperature increased considerably more than the cover-crop treatment due to sunny conditions. Heat stored in the soil then contributed to keeping higher air temperatures during the night of March 24.

\section{Nights cooler with cover crops}

In our experiment, removal of a 0.5 inch (0.0125-centimeter) depth of prunings from a citrus orchard floor increased the nighttime temperature relative to an orchard floor covered with prunings. The shielded temperature at 5-foot (1.5-meter) height within a tree canopy in the raked area was about $33.2^{\circ} \mathrm{F}\left(0.67^{\circ} \mathrm{C}\right)$ when the unraked temperature was $32^{\circ} \mathrm{F}\left(0^{\circ} \mathrm{C}\right)$. The difference in temperature between treatments was greater at lower temperature.

When a tall cover crop with $100 \%$ shading was compared to an orchard without a cover crop, the no-covercrop treatment had higher nighttime temperatures, and the difference was greater at lower temperatures (fig. 4).
The orchard without a cover crop is expected to have a $34.2^{\circ} \mathrm{F}\left(1.24^{\circ} \mathrm{C}\right)$ temperature when the orchard with a cover crop is at $32^{\circ} \mathrm{F}\left(0^{\circ} \mathrm{C}\right)$. Clearly, the removal of prunings and maintaining orchard floors clean of cover crops will provide between $0.9^{\circ} \mathrm{F}$ and $2.2^{\circ} \mathrm{F}\left(0.5^{\circ} \mathrm{C}\right.$ and $1.2^{\circ} \mathrm{C}$ ) of protection against freezing on many nights.

The results of this study suggest that a cover crop or mulch can lower minimum temperature at night, posing an increased threat from freeze damage. A $1.0^{\circ} \mathrm{F}$ difference in minimum temperature can result in a significant increase in damage to fruit during a freeze episode.

However, the cover crop or mulch may offer cultural benefits in overall crop production. Cover crops may increase water infiltration, mulches may reduce weed seed germination and either of the two may reduce erosion on hillsides. The disadvantages of a cover crop include (1) increased evapotranspiration, (2) increased rodent, snail and ant activity, (3) disruption of water application patterns (uniformity) and (4) greater potential for freeze damage. Clearly, selecting the appropriate orchard-floor management practice depends on a number of considerations relative to local conditions.

The decision to use wind machines on any given night depends on the nighttime temperature trend. Historical records demonstrate that each of these machines is operated about 100 hours during a typical freeze season. Higher minimum temperatures may be maintained by properly managing groundcover or eliminating cover crops and mulches, thereby reducing the need to use wind machines and the subsequent operation times. By using temperature forecast models that adjust for cover crops and mulches, the operation of wind machines can also be minimized to save time and money.

For orchards that are not actively protected, removing cover crops and mulch will reduce the chances of freeze damage. If a cover crop is necessary for some reason, planting late in the fall will minimize the potential for freeze damage. Late-fall-planted cover crops are shorter during freeze season

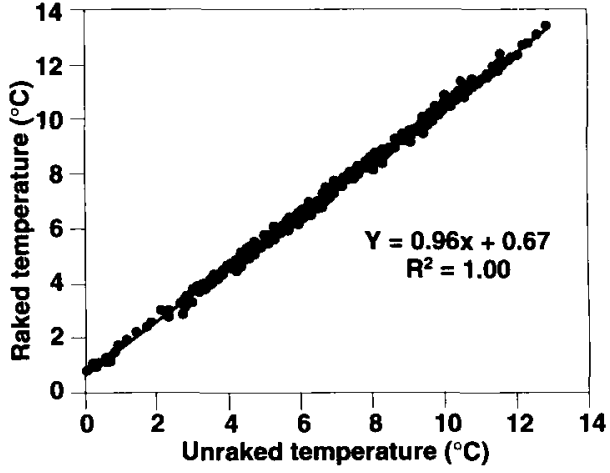

Fig. 1. Regression of raked versus unraked shielded temperatures during nighttime from the pruning removal experiment.

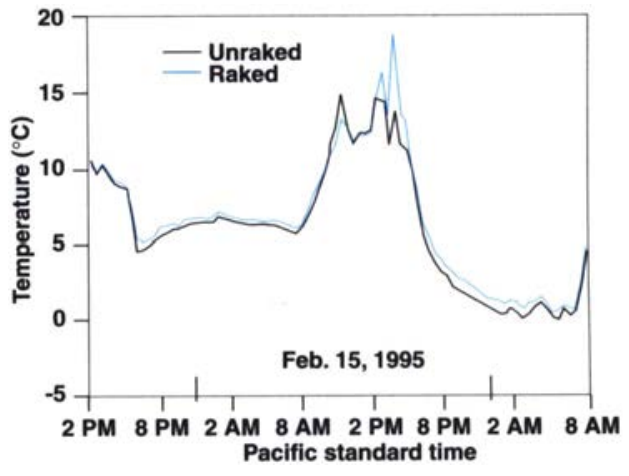

Fig. 2. Shielded temperature values measured in the raked and unraked treatments from 2 P.M. on Feb. 14 to 8 A.M. on Feb. 16, 1995.

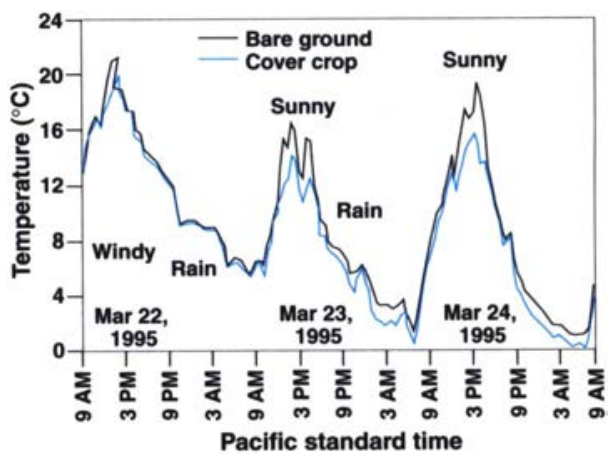

Fig. 3. Shielded temperatures for treatments with and without cover-crops from 9 A.M. On March 22 to 6 A.M. On March 25, 1995.

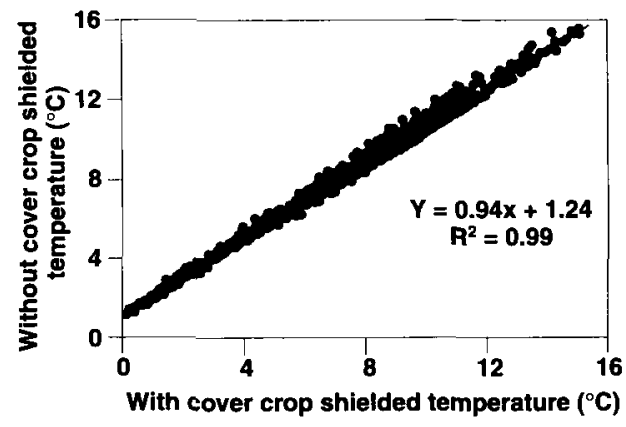

Fig. 4. Shielded nighttime temperatures for without-cover-crop plots versus with-covercrop plots, 1995. 


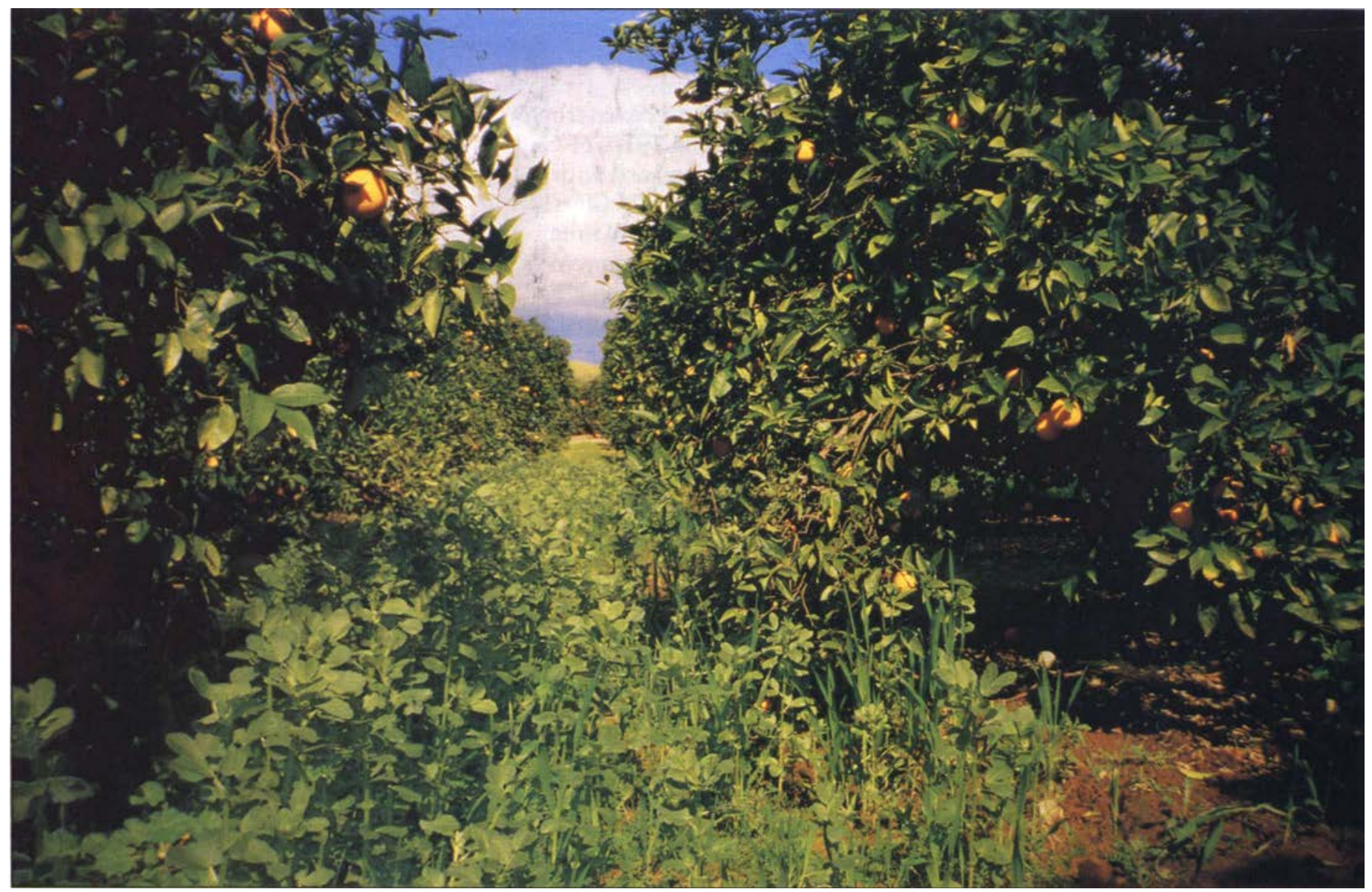

An orchard with a cover crop had lower nighttime temperatures than an orchard without a cover crop.

(November through mid-February) and the potential for damage is smaller than for earlier plantings, which allow the crop more time to grow.

N.V. O'Connell is Farm Advisor, UC Cooperative Extension, Tulare County; R.L. Snyder is Biometeorology Specialist, UC Davis.

The authors would like to thank Paramount Citrus, Badger Farming and C.E.
Kallsen for providing assistance in these experiments.

\section{References}

Cochran PH, Boersma L, Youngberg CT. 1967. Thermal properties of a pumice soil. Soil Sci Soc Amer Proc 31:454-9.

Donaldson DR, Snyder RL, Elmore C, Gallagher S. 1993. Weed control influences vineyard minimum temperature. Amer $\mathrm{J}$ Enol \& Vitic 44(4):431-4.

Fritton DD, Martsolf JD. 1981. Solar energy, soil management and frost protection. Hort Sci 3:205.
Fritton DD, Martsolf JD, Busscher WJ. 1976. Spatial distribution of soil heat flux under a sour cherry tree. Soil Sci Soc Amer J 40:644-7.

Gradwell MW. 1963. Overnight heat losses from the soil in relation to its density. New Zealand J Sci 6:463-73.

Pehrson JE. 1989. Groundcovers and orchard temperatures. Citrograph 75:14.

Snyder RL, Connell J. 1993. Groundcover height affects predawn orchard floor temperature. Cal Ag 47(1):9-12.

Snyder RL, Pruitt WO. 1992. Evapotranspiration data management in California. Session Proceedings/Water Forum 1992, ASCE.

Baltimore, MD/Aug. 2-6, 1992.

\section{CALIFORNIA AGRICULTURE ASSOCIATE EDITORS}

Animal, Avian, Aquaculture
\& Veterinary Sciences
Jim Cullor
Christopher M. Dewees
Kathryn Radke
Barbara A. Reed
Economics \& Public Policy
George Goldman
Richard A. Howitt
Alvin Sokolow
Food \& Nutrition
Amy Block Joy
Eunice Williamson
Sheri Zidenberg-Cherr

Human \& Community Development

Linda M. Manton

Karen P. Varcoe

Land, Air \& Water Sciences Mark Grismer

John Letey

Henry J. Vaux, Jr.

Natural Resources

Daniel W. Anderson

Lynn Huntsinger

Richard B. Standiford http://danr.ucop.edu/calag/

CALAG@ucop.edu

PH: 510 987-0044

FAX: 510 465-2659
Pest Management

Michael K. Rust

Robert Washino

Plant Sciences

Jodie S. Holt

Lee F. Jackson

G. Steven Sibbett 